\title{
THE EFFECTS OF DIFFERENT VEGETATION TYPES ON LOCAL CLIMATE
}

\author{
ANDRÁS BÉLA OLÁH \\ Corvinus University of Budapest, Department of Garden and Open Space Design, Faculty \\ of Landscape Architecture, 35-43 Villányi Str. Budapest 1118, Hungary, Tel.: +36 30658 \\ 45 82, Email: olah.andras.bela@gmail.com
}

Received: $2^{\text {nd }}$ September 2010, Accepted: $29^{\text {th }}$ September 2011

\begin{abstract}
In the present days the effects of the global climate change can be observed everywhere. The negative impacts of this phenomenon, especially temperature rising, can be felt significantly in the cities of Central Europe. In these areas the effects of the global temperature rising and the urban heat island intensify each other.

However, these phenomena grant the opportunity to find the most suitable vegetation types for moderating the warming up of such urban areas. The aim of this study is to provide support in determining these vegetation types.

The examined area is Budapest, the capital of Hungary. This city has a wide selection of various urban green surfaces; consequently as a result of the examination it shall become clear which of these are the best vegetation types and the best vegetation structures in respect of the positive climatic effects. With the help of this study it shall also be clarified how the strength of this moderating effect depends on the water supply of the plants. The importance of this question lies within the fact that depending on the water supply different vegetation types may have totally different effects. Thus the main plant species and the structure of the canopy layers must be taken into thorough consideration.

A collection of thermal infrared satellite images serve as the main source of data for this study. These images were produced in the last decade. They thoroughly show the thermal attributes of the examined area (green surface). The other important source of information is the examination of those structure species and vegetation types which are the most efficient in reducing the negative climate impacts under urban circumstances. The water supply dependence of this reducing effect is also very important piece of information.
\end{abstract}

Key words: various vegetation types, urban heat island, thermal infrared satellite images, Budapest, Hungary

\section{INTRODUCTION}

It is well known that towns and especially cities remarkably modify the climate circumstances of their environment. This modifying effect is very complex; the results can generally be mentioned in connection with it: proceeding towards the inner parts of a city the temperature increases and becomes significantly higher than in the outer parts of the city (although this impact depends on other macroclimatic effects as well); this 
phenomenon is the so-called urban heat island (Unger and Pongracz 2008). The decrease in relative humidity, the decreasing rate of the ventilation through the city and the increasing rate of the air pollution are further important attributes of this changing effect.

In this study the temperature and heat distribution on different urban surfaces has been measured, although the climate itself has several other very important attributes. However in case of cities the temperature and heat is that factor which is the most changed and this changing has remarkable effect on the livability of these cities. Other important factors, just like air-humidity, quantity and distribution of rainfall, air quality and pollution, etc. are also very important, but the problem of the urban heat island is by far the greatest challenge for the inhabitants of the settlements.

Considering the temperature in detail, at the same time it has also been recognized that vegetation in urban zones reduce these negative local climate effects, which briefly means that plants ameliorate the urban climate (Dobi et al 2009). The climate modifying ability of the vegetation can be truly significant; however, this impact is also very complex. In the following parts of the paper the thermal modifying effects of vegetation on the urban heat balance shall be discussed in detail. Basically, plants can contribute to the improving of the thermal attributes in their environment in three ways. The first way is photosynthesis itself, meaning that the predominant part of the incoming solar energy is transformed into chemical energy and not into heat. Although during the photosynthesis the plant can use up only a well separated part of the spectrum of the incoming radiation (PAR), but because of the whole incoming radiation would turn into heat in any other case, the photosynthesis can this way truly ameliorate the energy balance and lower the heat (temperature) around the plants. The second way is vaporization (evapotranspiration) of the plants, which has a significant cooling effect on the environment of the plants. The third way, which is interconnected with the structure of the canopy layers of the vegetation, is the shading effect. In the case of expansive grassy areas, this third way is out of question, but in the case of a tree stand with a closed canopy layer the land surface is totally shaded, thus it is unaffected by direct solar radiation, furthermore an additional and relatively cold air layer also appears above the land surface (this layer is a couple or 10s of metres thick). Although the satellite images can provide information only about the surface, which is the canopy layer of the tree stands in this case, considering the fact that the temperature raising originates basically from solar radiation, it can be correctly assumed that the temperature under the closed canopy layers is not higher than thatmeasured on the canopy level.

In the following parts of the paper the exact effects of variaous vegetation types on the heat distribution will be surveyed in detail, furthermore, the rate and significance of these effects reducing the urban heat island shall also be examined.

\section{MATERIAL AND METHODS}

\section{The surveyed area}

The site of the examination is Budapest, the Capital of Hungary. This city is located in Central Europe, in the temperated zone, and its climate is influenced by all continental, oceanic and the mediterranean effects. Basically, this settlement is located in a basin, thus it is surrounded by mountains and hills except for the southern, south-eastern direction. The city can be divided into two parts. The western part is mostly hilly (the Buda side), while the eastern part (the Pest side) is almost plain. The two parts are separated by the River Danube. 
The vegetation, the soil and the relief are all highly diverse. As numerous landscape types can be found here, the original vegetation used to be very diverse as well, including mountain beech groves, hill oak yards, karstic forests, floodplain forests and even lowland oak yards (Schmidt 2003).

Fig. 1: The Districts of Budapest and the Google Map of the City
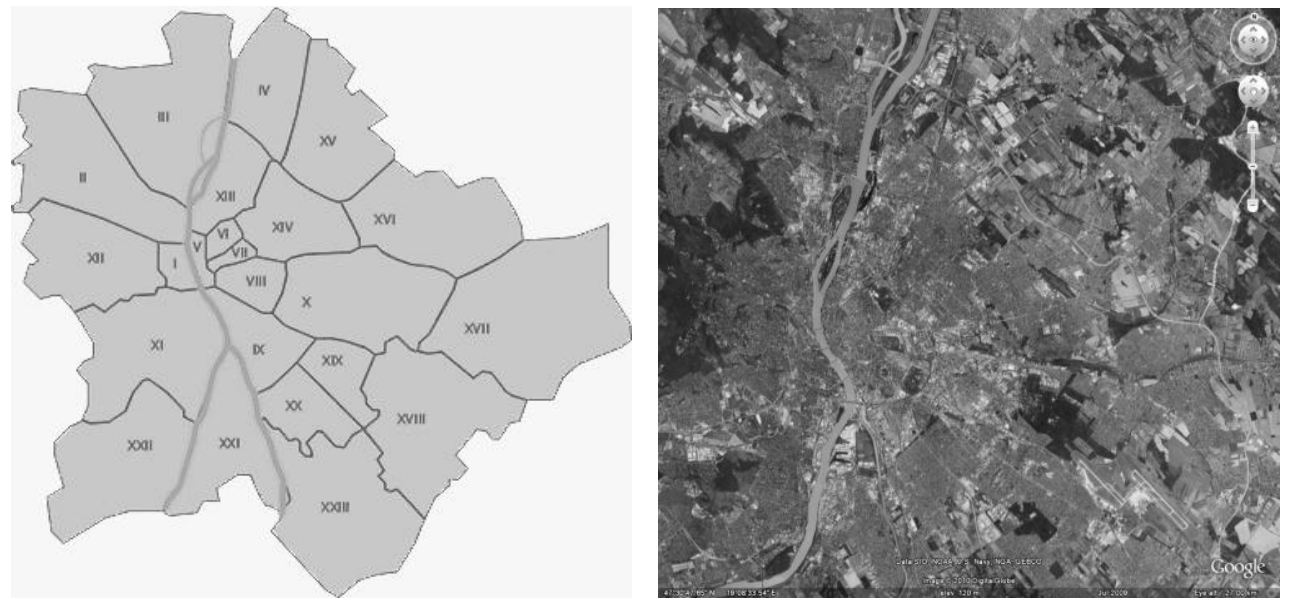

The eastern part of the City (the Pest side) will be examined in detail, first of all because the urban heat island reaches its highest level in this area, where the original flora has been least preserved. On the other hand, this area is the most suitable one to survey the climate modifying effects of various vegetation types with the applied method. On the Buda side the diverse relief has a significant additional effect on the heat distribution.

\section{Fig. 2: The examined sites on the Pest side of the City}

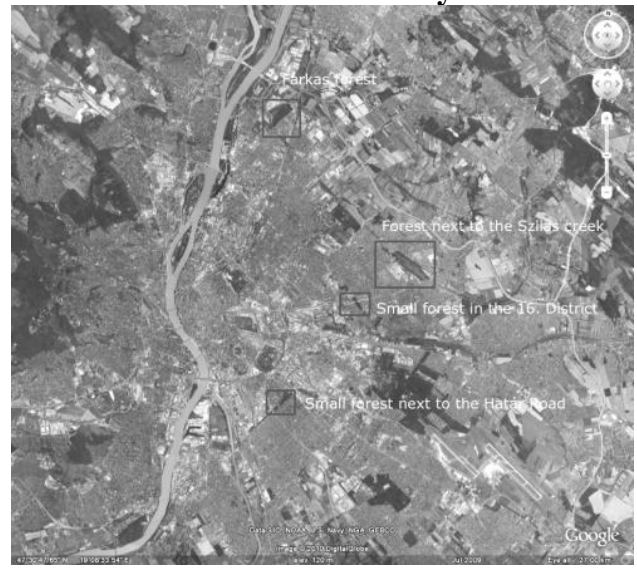

On the Pest side practically the entire existing vegetation is fully planted, and considering its composition, it totally differs from the original native vegetation. A great part of the vegetation consists of black locust forests which have been planted onto sandy soils; also poplar forests planted on creek banks can be found here. Furthermore, some remaining 
native oak yards are also situated in the area. These vegetation types will be the objects of our examination (Csepely-Knorr 2010).

Four almost homogenic green surfaces will be discussed in detail. The first is a relatively young (20-year-old) poplar forest next to the Szilas Creek, the second is an older (50-yearold) black locust forest in the $16^{\text {th }}$ District, the third is also a black locust forest of similar age next to Határ Road (on the border of the $9^{\text {th }}$ and $19^{\text {th }}$ Districts) and the last one is the Farkas Forest, which is a relatively older (60-year-old) lowland oak yard in the northern part of the City $\left(4^{\text {th }}\right.$ District). These four examined areas thoroughly represent the tree species and tree stands of the eastern part of the city, moreover the tree stands are almost totally homogenous on these sites, consequently the reserch of these areas also provides the opportunity to gain some information on the particular effects of these tree species. It is a great advantage that, in these cases, relief effects do not have to be taken into consideration.

\section{THE METHODS}

The surveying process was completed with the help of infrared satellite images. The great advantage of such images is that it is not necessary to develop a dense surface measuring network, however, their disadvantage in the respect of the examination is that producing a usable image highly depends on weather conditions (in cloudy weather no useful satellite images can be produced). The other disadvantage of these images is their spatial resolution, which sets a limit to the examination.

The satellite images used for the survey are so called thermal infrared satellite images, which come from the NASA Database (NASA 1999). It is very important to note that the temperature values featured on the images are not equivalent to ordinary meteorological temperature values (measured on a 2 metres high level in shade), since they are surface kinetic temperature values which have been derived from the radiation of the surface. Fortunately, in respect of the examination the difference between the two kinds of temperature values is not significant, the results of comparing them show that the greatest difference between the two kinds of temperature values is only approx. $1-1.5^{\circ} \mathrm{C}$ (Dobi et al 2009). It is also very important that the spatial resolution of these satellite images is 90 metres, which can be considered relatively fine from the meteorological point of view, however in respect of urban planning and architecture it sets a limit to examinations.

Four satellite images were processed as part of the survey. These images represent Budapest in different times, all shot in the morning at 09:44 am. The dates of the photos are $6^{\text {th }}$ July 2001, $4^{\text {th }}$ May 2002, $18^{\text {th }}$ June 2006 , and $6^{\text {th }}$ May 2008. There should have been 16 pictures from the four sites in four different periods, however unfortunately only 12 images proved to be useful (the other 4 are unusable due to the small clouds or to the fact that the examined area was outside the borders of the image).

The Google Earth Map (http://maps.google.com/) was also used in order to adjust the thermal images to the territory (and to localize the different places with different temperature values).

During the process of examination, so-called thermal cross sections were produced in order to indicate the change of the typical heat distribution along a given line (the cross section line). Three typical thermal cross sections were produced in the case of all sites and all measuring dates. These represent the rows (or coloumns) of the temperature values beside one another on the satellite images. Considering the fact that one such a pixel 
represents a $90 \times 90$ metres territory, thus such a thermal cross section provides the data of the heat distribution of a $270 \mathrm{~m}$ wide surface zone. On the following graph on the vertical axis can be seen the temperature values, while on the horizontal axis can be seen the number of the pixels (each is 90 wide). On all of these graphs there can be found three lines, which repesent the three neighbouring bands that provide together the $270 \mathrm{~m}$ wide examined surface zone.

Fig. 3: Thermal infrared satellite images, taken on $6^{\text {th }}$ July 2001 and $4^{\text {th }}$ May 2002
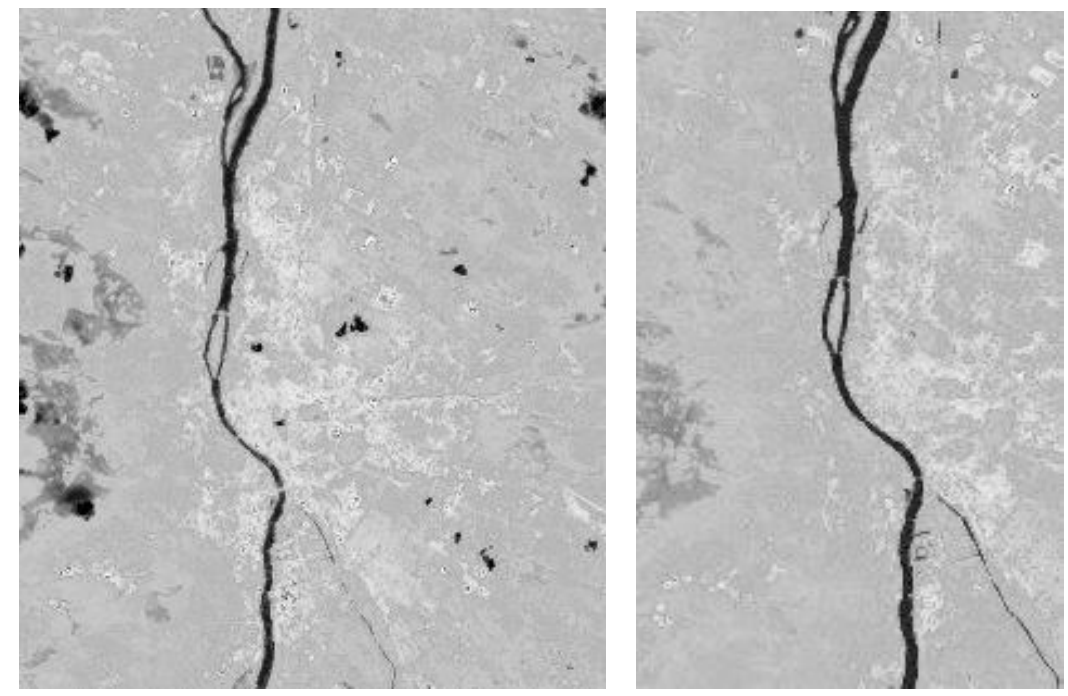

Fig. 4: Thermal infrared satellite images, taken on $18^{\text {th }}$ June 2006 and $6^{\text {th }}$ May 2008
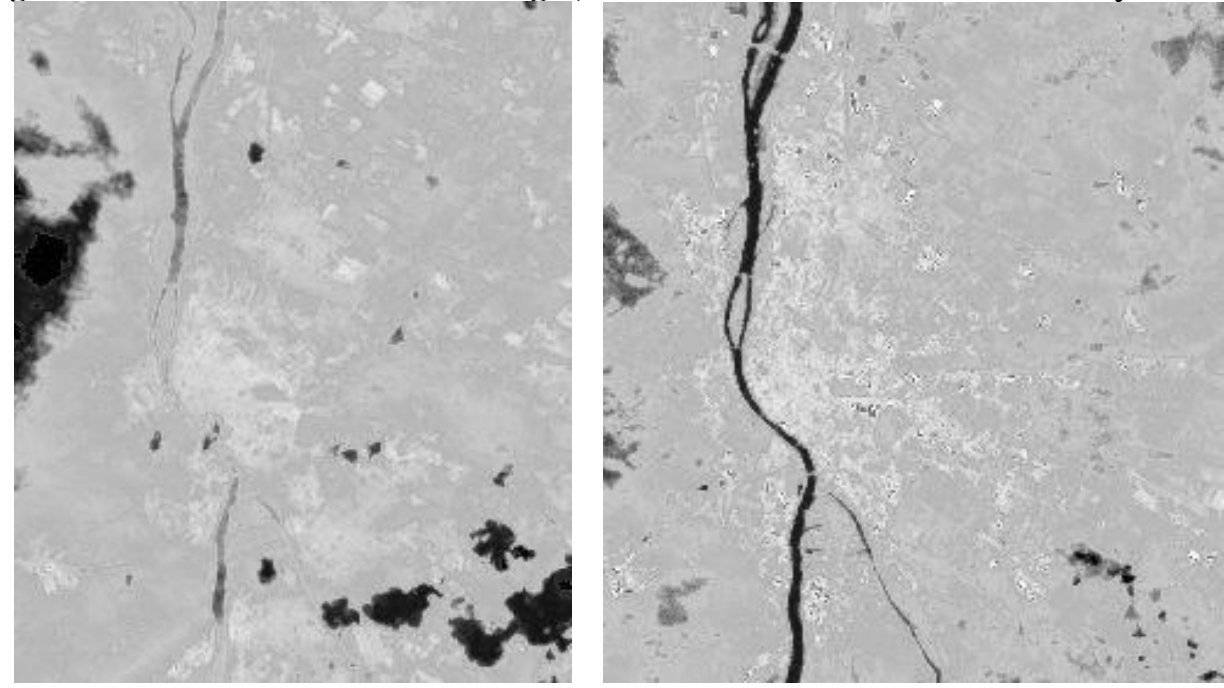


\section{RESULTS}

\section{The poplar forest along the Szilas Creek ( 80 acres):}

This area is located along the Szilas Creek in the eastern side of the city in the $16^{\text {th }}$ District. It is typically covered by approx. 10-20 years old grey poplars (Populus $x$ canescens). Some grassy areas can be also found here, especially on the banks of the creek. It is very important to note that even though the area is not irrigated, still the water supply of the vegetation is very good due to the creek flowing through the forest and consequently the relatively high underground water level.

Fig. 5: The poplar forest on the banks of the Szilas Creek with the thermal cross section line

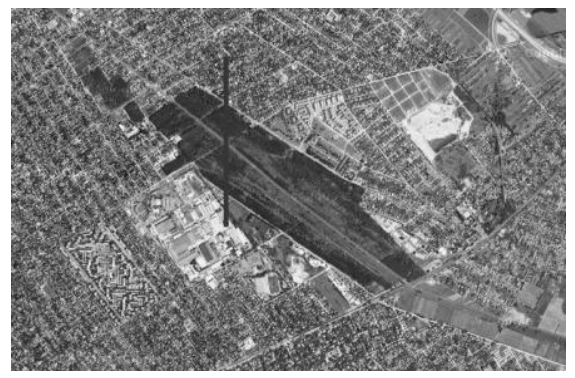

The following can be stated according to the thermal cross section based on the thermal infrared satellite image, which was produced on $6^{\text {th }}$ July 2001: it is clearly visible that the temperature of the built-in neighbouring zones was significantly higher (approx. $35-37{ }^{\circ} \mathrm{C}$ ) than the temperature of the area of the forest, which was only approx. $28-31{ }^{\circ} \mathrm{C}$. It is important to note that in the central zone, on the banks of the creek which were covered only by grass the temperature was slightly higher $\left(31^{\circ} \mathrm{C}\right)$. Thus, in this case a significant, 6-7 ${ }^{\circ} \mathrm{C}$ difference can be seen in the temperatures between the poplar forest with an abundant water supply and the built-up (garden city-like) areas.

Fig. 6: The typical thermal cross sections of the forest along the Szilas Creek on $6^{\text {th }}$ July 2001

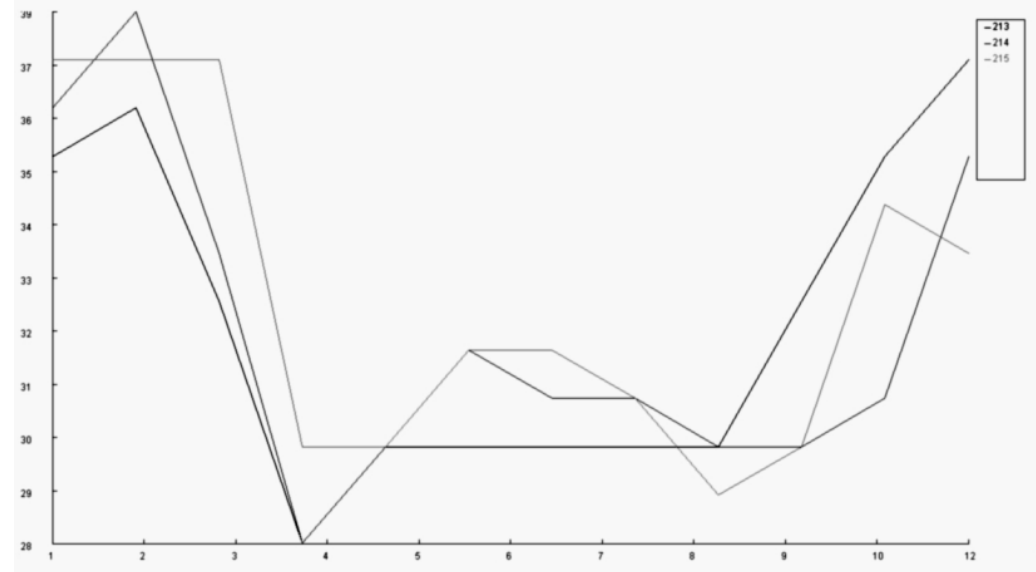


On the satellite image taken on $4^{\text {th }}$ May 2002 this area was outside the sensor's field of vision.

The results of processing the image produced on $18^{\text {th }}$ June 2006 show that the temperature of the surrounding built-in areas was about $33-37{ }^{\circ} \mathrm{C}$, while the temperature of the forest was only $26-29{ }^{\circ} \mathrm{C}$, thus the typical thermal difference was approx. $7-8{ }^{\circ} \mathrm{C}$; furthermore, it is also clearly visible on this thermal cross section that the inner grassy zone was approx. $2-3{ }^{\circ} \mathrm{C}$ warmer than the tree stands.

Fig. 7: The typical thermal cross sections of the forest along the Szilas Creek on $18^{\text {th }}$ June 2006

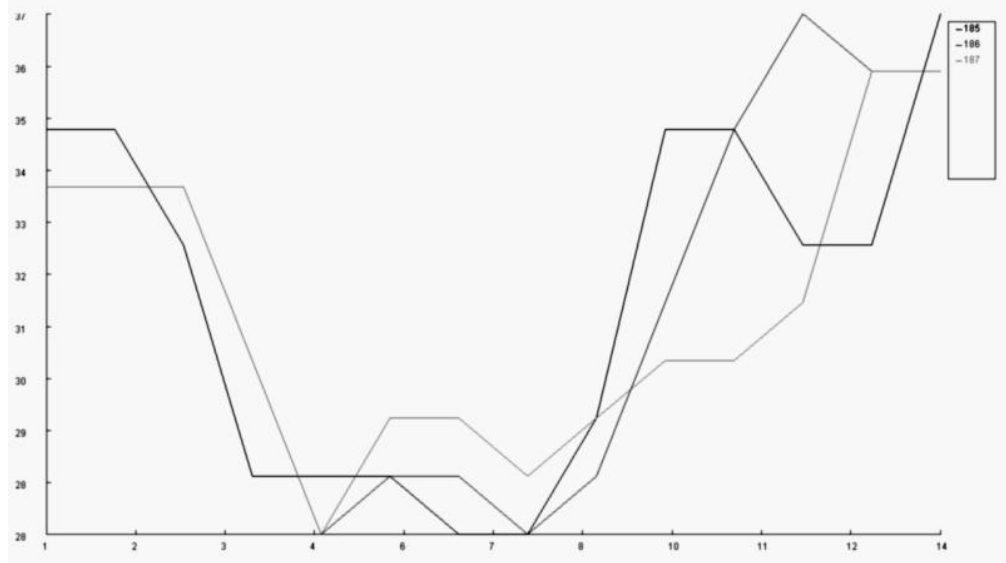

Fig. 8: The typical thermal cross sections of the forest along the Szilas Creek on 6th May 2008

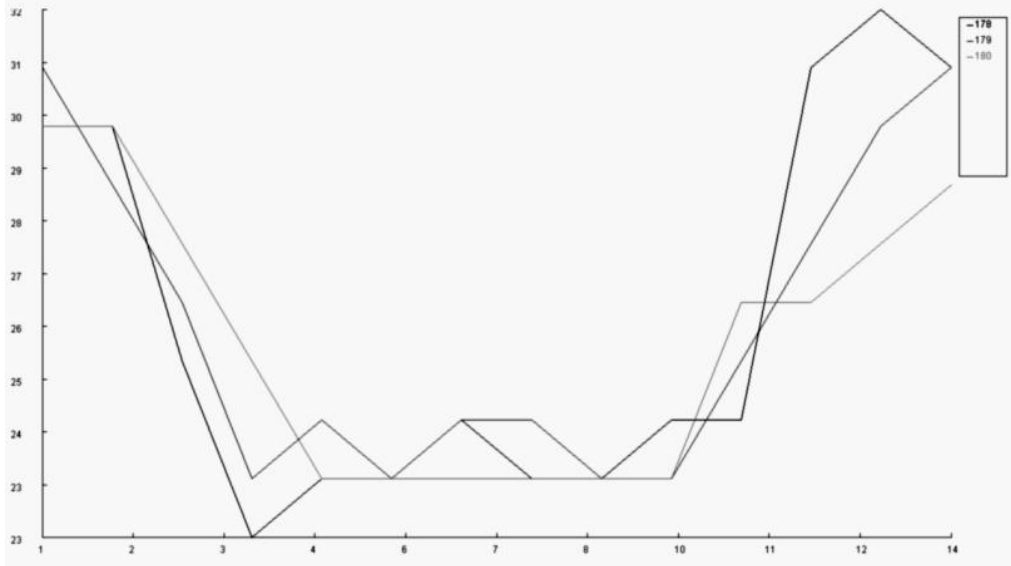

Finally, the processing of the last satellite image taken on $6^{\text {th }}$ May 2008 showed the following results: similarly to the two former cases the area of the forest was significantly cooler than the surrounding built-in areas in this case as well; furthermore it is also visible that the central grassy areas were $1-2{ }^{\circ} \mathrm{C}$ warmer than the tree stands. The temperature 
of the surrounding, garden city-like areas was about $29-31{ }^{\circ} \mathrm{C}$, while the temperature of the forest was only about $23-24{ }^{\circ} \mathrm{C}$. According to these results the afforested zones were also significantly cooler by approx. $6-7^{\circ} \mathrm{C}$ than the surrounding urban zones.

In the case of examining this young poplar forest along the Szilas Creek it can be stated that the temperature of the forest was significantly cooler than the neighbouring built-in (garden city-like) zones. On the other hand, the grassy area was significantly warmer than the afforested zones with approx. $1-3{ }^{\circ} \mathrm{C}$, despite the fact that the grassy area had the best water supply due to its direct location on the banks of the creek and due to the cooling effect of the water surface, which also affected the temperature (Csepely-Knorr et al 2010).

\section{The small black locust forest $\left(10\right.$ acres) in the $16^{\text {th }}$ District}

An approx. 40-50 years old, relatively little, planted black locust forest (Robinia pseudoacacia) stands on this site on not poor quality sandy soil; however the level of the underground water is relatively high due to the proximity of the Rákos Creek. The majority of the green surfaces on the Pest side consist of similar vegetation.

\section{Fig. 8: The small black locust forest in the $16^{\text {th }}$ District with the thermal cross section line}

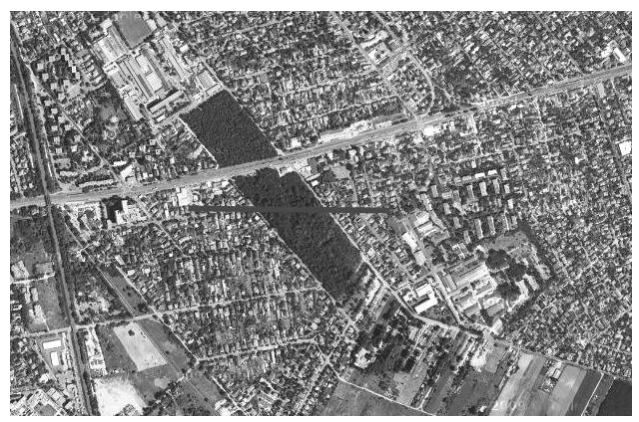

The processing of the thermal infrared satellite image taken on $6^{\text {th }}$ July 2001 shows that the temperature of the afforested area was approx. $29-30{ }^{\circ} \mathrm{C}$, while the temperature of the neighbouring garden cities was approx. $35-40{ }^{\circ} \mathrm{C}$. The locations of the minimum values of the neighbouring thermal cross sections slightly differ from each other, which can be explained by the relatively small size of this forest. The significant temperature difference was approx. $6-10^{\circ} \mathrm{C}$ in this case.

In the case of the image taken on $4^{\text {th }}$ May 2002 this area was out of the sensor's field of vision and in the following case on $18^{\text {th }}$ June 2006 there was a small cloud above this area, thus it was impossible to gain any useful information on this small urban forest.

On the image taken on $6^{\text {th }}$ May 2008 the small forest was fortunately clearly detectable and measurable. The processing of this image led to the following results: the minimum values of the three parallel thermal cross sections are again not on the same spot, similarly to the former graph, and this proves that the 90 metres spatial resolution is relatively rough in the case of such small areas. In the current case the temperature was approx. $24-25^{\circ} \mathrm{C}$ in the inner parts of the forest, while it was approx. $29-33{ }^{\circ} \mathrm{C}$ in the neighbouring built-in zones. Thus it is clear that the forest was approx. $5-8{ }^{\circ} \mathrm{C}$ cooler than the surrounding garden city zones. 
Fig. 9: The typical thermal cross sections of the small black locust forest in the $16^{\text {th }}$ District on $6^{\text {th }}$ July 2001

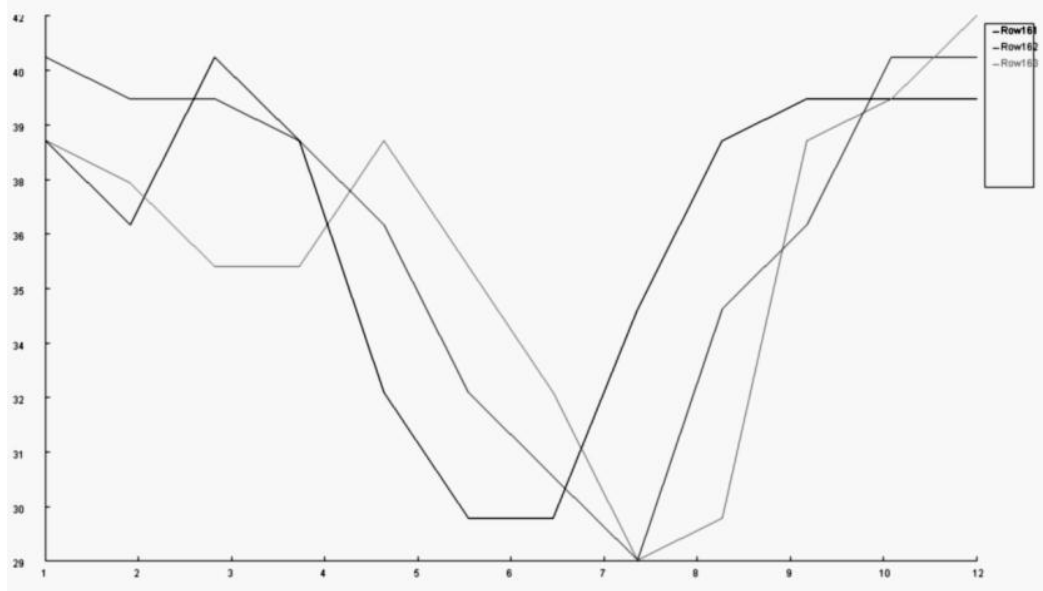

Fig. 10: The typical thermal cross sections of the small black locust forest in the $16^{\text {th }}$ District on $6^{\text {th }}$ May 2008

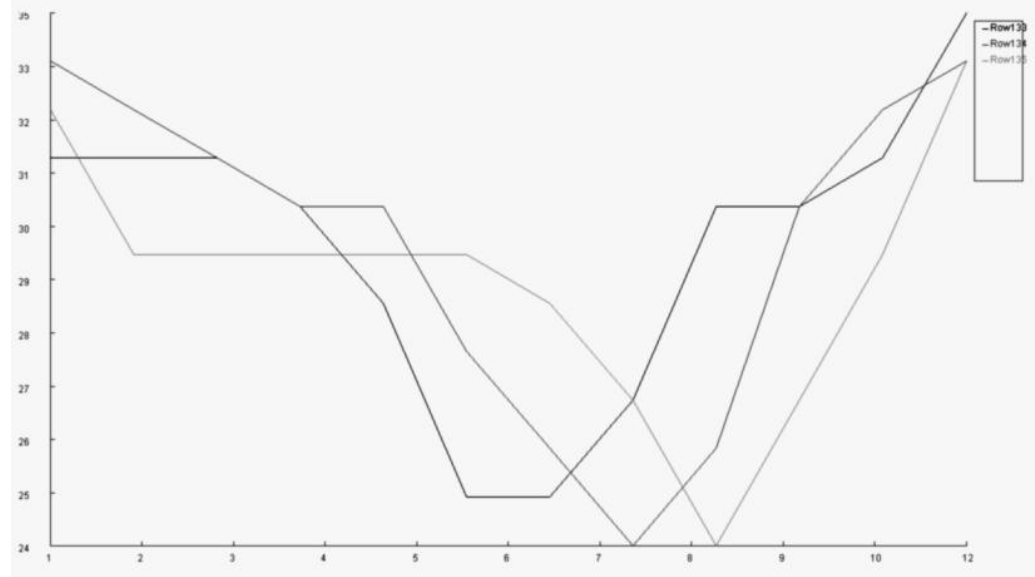

To sum up the measurements of the small black locust forest in the $16^{\text {th }}$ District it can be stated that the tree stand was remarkably cooler than the surrounding residential zones by approx. $5-10{ }^{\circ} \mathrm{C}$ and this cooling effect was detectably stronger (by approx. $2{ }^{\circ} \mathrm{C}$ ) than in the spring case.

The black locust forest zone beside Határ Road on the border of the $9^{\text {th }}$ and $19^{\text {th }}$

\section{District}

This narrow forest zone used to be the border of the Capital in the first half of the $20^{\text {th }}$ century; this means that this area has been afforested for a long time. The age of the tree 
stand is similar to the former case (40-50 years old), but the level of the underground water is much lower. The width of the tree zone is not constant; it varies between 200-300 metres.

Fig. 11: The black locust forest zone beside Határ Road with the thermal cross section line

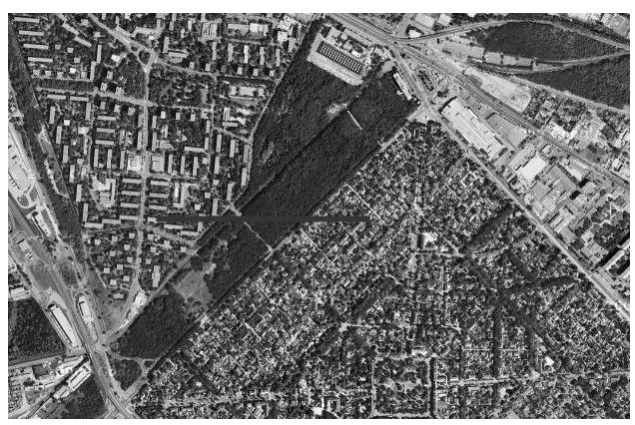

The following results were obtained during the processing of the satellite image taken on $6^{\text {th }}$ July 2001: the temperature of the forest zone was approx. $27-31{ }^{\circ} \mathrm{C}$, while the temperature of the bordering garden city and brown field was approx. $33-38{ }^{\circ} \mathrm{C}$. So, in this case the typical temperature difference was approx. $6-7^{\circ} \mathrm{C}$, but the values in this case showed much greater dispersion than in the previous cases.

Fig. 12: Typical thermal cross sections of the black locust forest zone beside Határ Road on $6^{\text {th }}$ July 2001

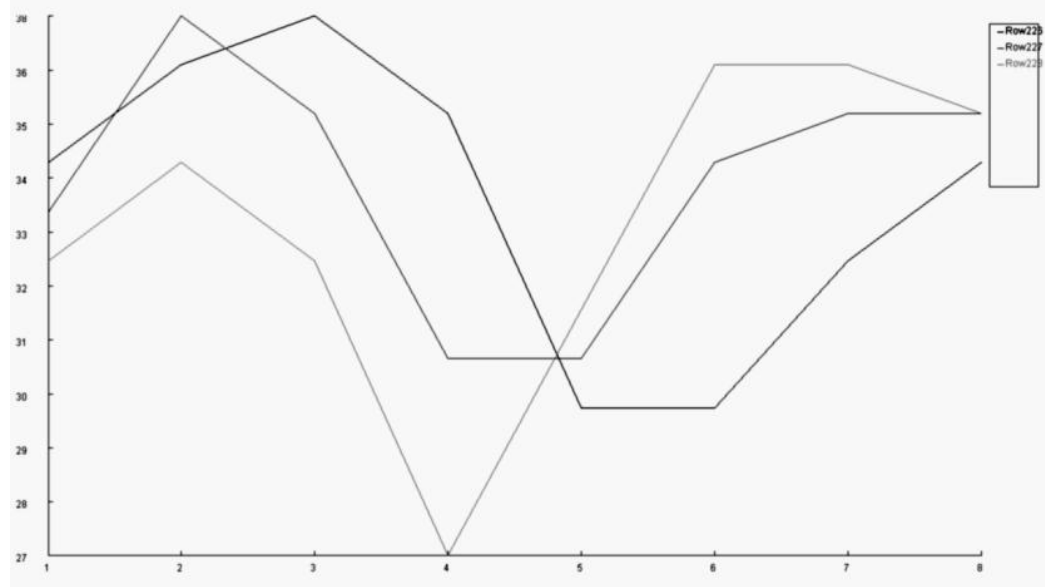

The following results were achieved during the processing of the satellite image taken on $4^{\text {th }}$ May 2002: both the value and the location of the minimums of the thermal cross sections significantly differ from each other. Generally, the temperature of the afforested zone was approx. $27-29^{\circ} \mathrm{C}$, while the temperature of the bordering zones was approx. 31 $37{ }^{\circ} \mathrm{C}$. Thus the afforested zone was approx. $4-8{ }^{\circ} \mathrm{C}$ cooler than the surrounding, built-up sites. 
Fig. 13: The typical thermal cross sections of the black locust forest zone beside Határ Road on $4^{\text {th }}$ May 2002

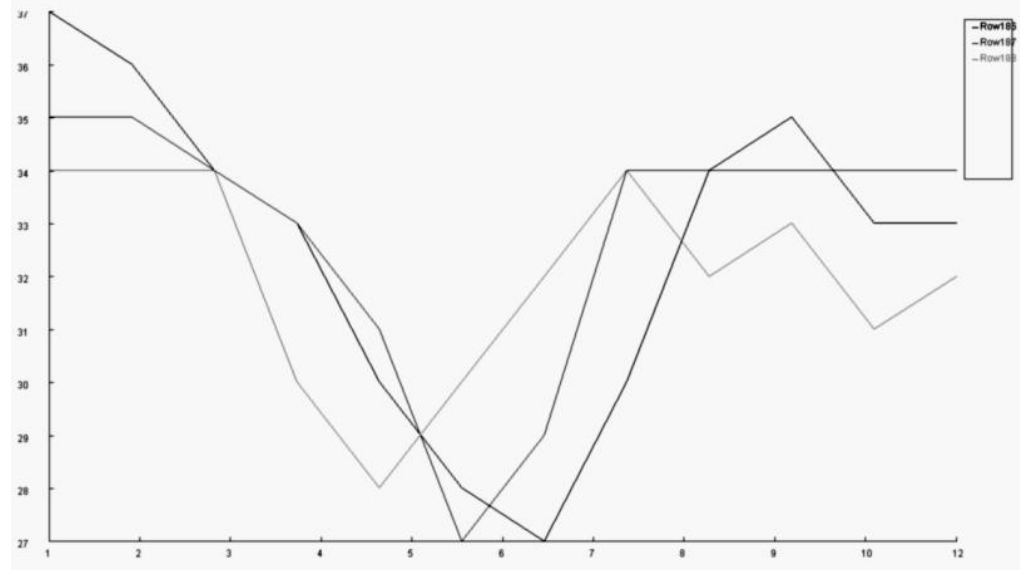

It was impossible to gain any useful information on this area from the image produced on $18^{\text {th }}$ June 2006 due to cloud covering.

On the next picture taken on 6th May 2008 the examined area was clearly visible and measurable. The following results were achieved during the processing: the temperature of the afforested zone was approx. $23-24{ }^{\circ} \mathrm{C}$, while approx. $26-30{ }^{\circ} \mathrm{C}$ in neighbouring garden city and on the other side of the forest; the temperature of the brown field was even higher, it was $30-35{ }^{\circ} \mathrm{C}$. Thus the temperature of the forest zone approx. $3-6{ }^{\circ} \mathrm{C}$ was lower than the neighbouring garden city and $7-11^{\circ} \mathrm{C}$ (!) lower than the other neighbouring site, the brown field.

Fig. 14: The typical thermal cross sections of the black locust forest zone beside the Határ Road on $6^{\text {th }}$ May 2008

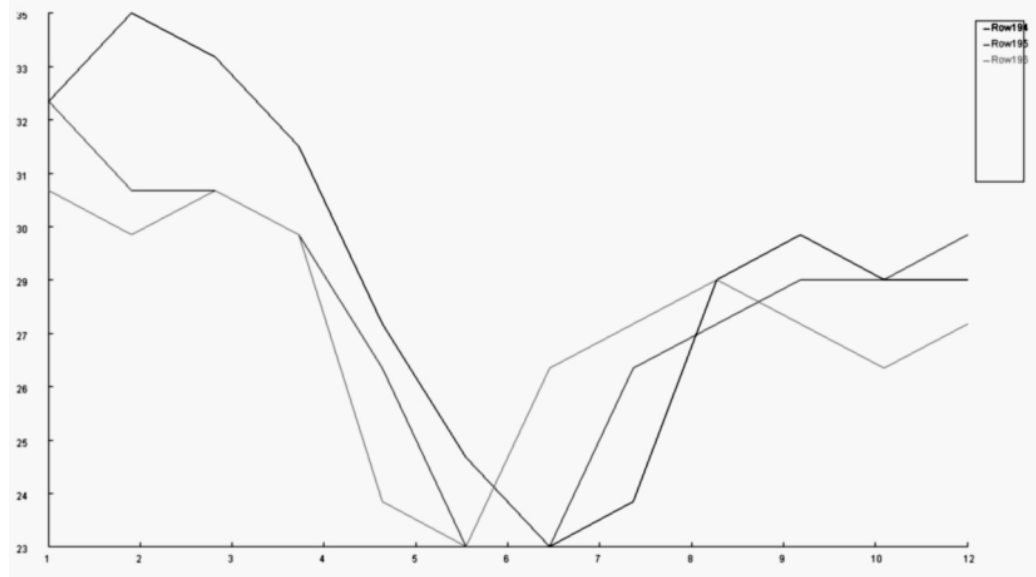


Summarizing the case of the black locust forest zone beside Határ Road the following can be stated: the temperature of the tree stand is significantly cooler than the temperature of the surrounding areas in this case too. However a difference occurred in the case of the bordering areas, as the brown field was significantly hotter than the garden city (Olah 2010). Generally, it can be said that the temperature of the afforested areas was approx. 3-8 ${ }^{\circ} \mathrm{C}$ lower than the neighbouring garden city, and when comparing it with the neighbouring brown field this temperature difference was even bigger. Furthermore it must be noted, that these temperature differences show great seasonal and spatial dispersion too.

\section{The Farkas forest (100 acres) in the $4^{\text {th }}$ District}

This site is covered by an approx. 60 years old oak forest with an almost unbroken canopy layer. Housing estates and newly built garden cities are located on the surrounding sites. The soil is predominantly sandy, but the level of the underground water is accessible, especially for oak species. This tree stand mostly consists of English oak (Quercus robur). The relatively high level of the underground water is related to the proximity of the River Danube.

Fig. 15: The Farkas Forest in the IVth District with the thermal cross section line

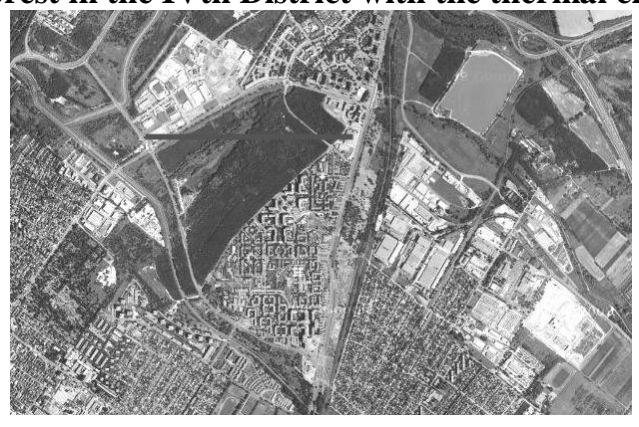

The following results were obtained during the processing of the satellite image taken on $6^{\text {th }}$ July 2001: the territory of the forest was relatively very cool $\left(26-28{ }^{\circ} \mathrm{C}\right)$, and the only sites where it reached $30{ }^{\circ} \mathrm{C}$ are those, where the crown canopy layer was not continuous. The neighbouring garden cities and housing estates were approx. $35-40{ }^{\circ} \mathrm{C}$ hot, so the typical temperature difference was approx. 9-12 ${ }^{\circ} \mathrm{C}(!)$.

The following results were obtained during the processing of the satellite image taken on 4th May 2002: the temperature of the forest was about $27-29{ }^{\circ} \mathrm{C}$ except for those areas where the crown canopy layer was not continuous. The temperature value in these areas was approx. $2-4{ }^{\circ} \mathrm{C}$ higher. The temperature of the surrounding residential zones was approx. $35-41{ }^{\circ} \mathrm{C}$. This means that the forest was $8-12{ }^{\circ} \mathrm{C}(!)$ cooler than the surrounding built-up areas. 
Fig. 16: The typical thermal cross sections of the Farkas Forest on $6^{\text {th }}$ July 2001

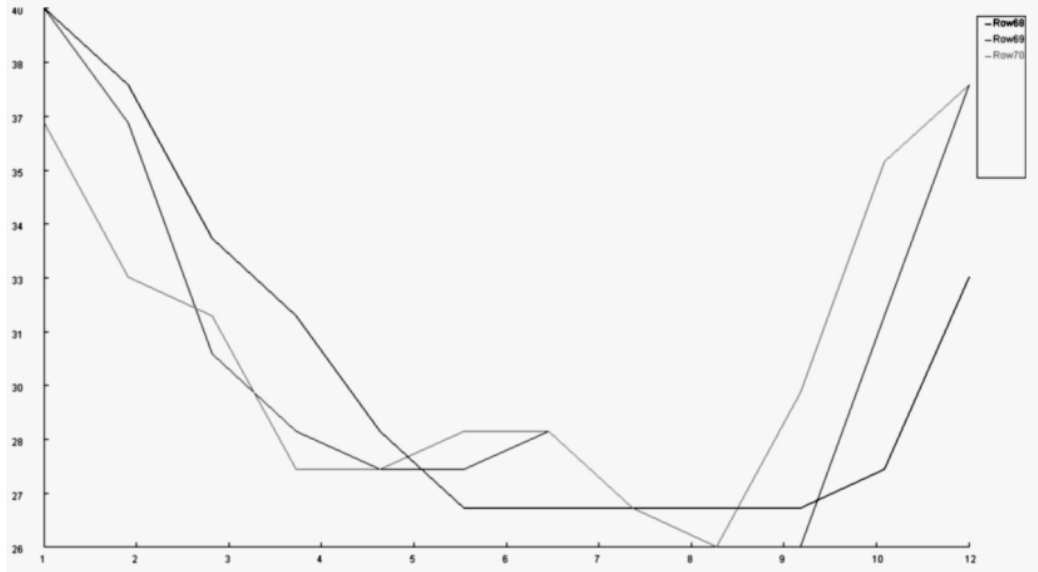

Fig. 17: The typical thermal cross sections of the Farkas Forest on $4^{\text {th }}$ May 2002

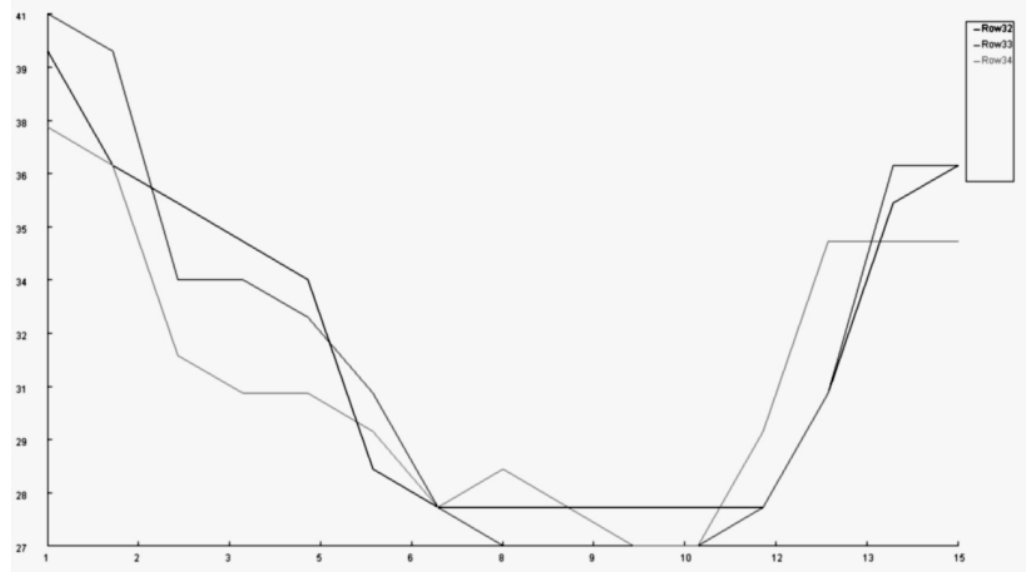

The following results were obtained during the processing of the satellite image shot on $18^{\text {th }}$ June 2006 : the temperature of the afforested zones was typically $28-29{ }^{\circ} \mathrm{C}$, while $35-41$ ${ }^{\circ} \mathrm{C}$ in the surrounding areas, which means that the typical temperature difference was approx. $7-12{ }^{\circ} \mathrm{C}$. This time there wasn't any remarkable difference between the sites with broken and unbroken crown canopy layers. 
Fig. 18: The typical thermal cross sections of the Farkas Forest on $18^{\text {th }}$ June 2006

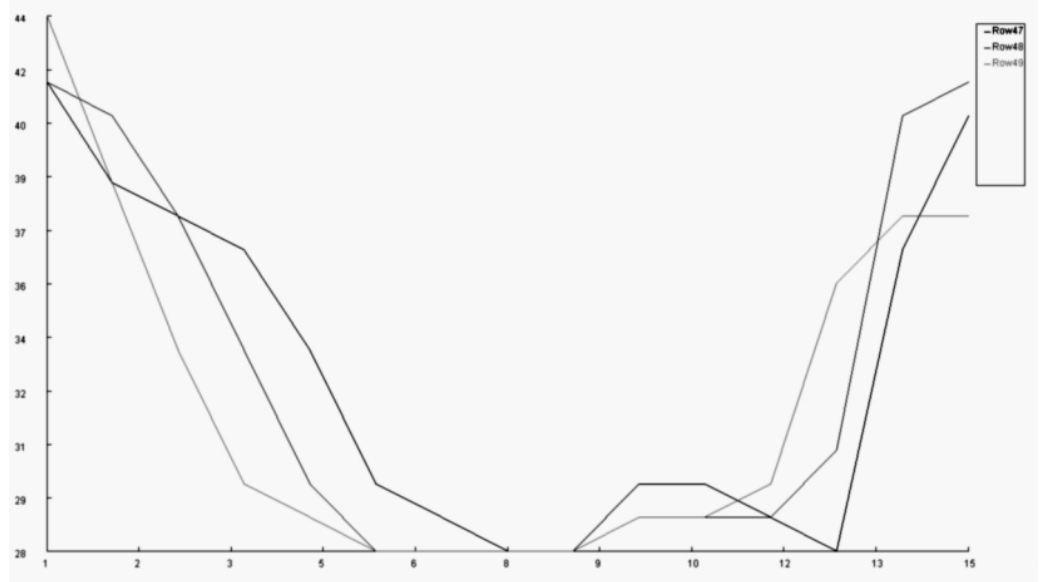

Finally, the following results were obtained during the processing of the satellite image shot on $6^{\text {th }}$ May 2008: the temperature of the forest was approx. $23-26{ }^{\circ} \mathrm{C}$, while the bordering residential zones were $35-44{ }^{\circ} \mathrm{C}$ (!) hot. Those sites, where the crown canopy layer was not continuous, did not show any difference in this case. The typical temperature difference was approx. $11-18^{\circ} \mathrm{C}(! ! !)$.

Fig. 19: The typical thermal cross sections of the Farkas Forest on $6^{\text {th }}$ May 2008

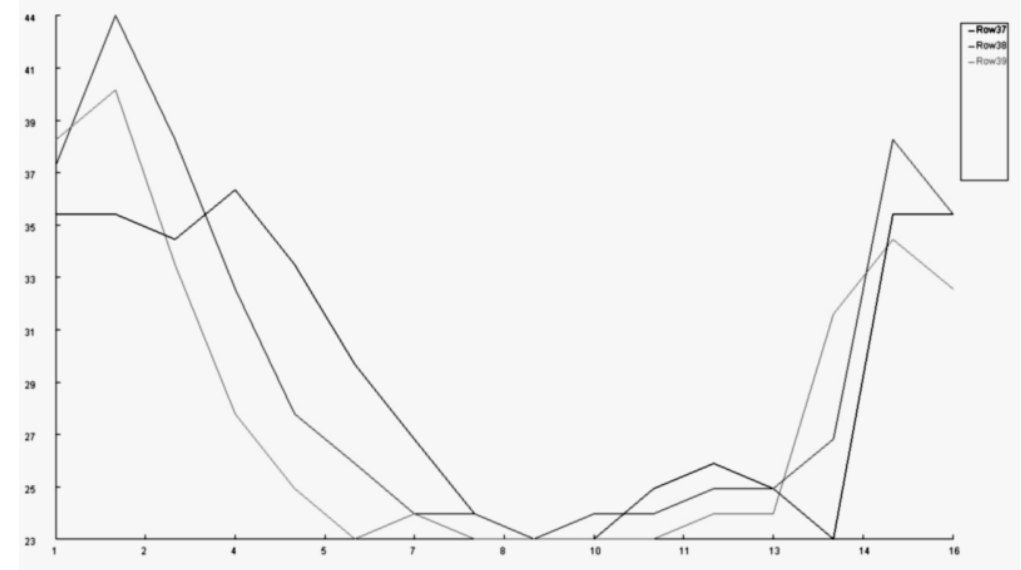

As a summary of the results of examining the Farkas Forest the following can be stated: the greatest cooling effect of approx. $7-18^{\circ} \mathrm{C}$ (!) was recognized in the current case, in which the tree species were mostly oak, and the roots had surely reached the underground water. 


\section{DISCUSSION}

Very interesting results have been gained from examining variousvegetation types and their effects on the temperature distribution and heat balance.

First of all it must be declared that the Heat Island reducing effect of the urban vegetation covering has been proven again, which is in full accordance with other studies, like the thesis of T. Gal (Gal 2009) and the article of Szegedi and Gyarmati (Szegedi 2009).

In the case of the young poplar forest along the Szilas Creek, it can be stated that even such a young forest has a remarkable cooling effect, especially if the water supply for the plants is sufficient. It is also very important to note that here the main tree species are the grey poplar (Populus $x$ canescens), for it is a well known fact that the vaporizing ability of poplars is extremely good in case the water supply is sufficient (Ogunjemiyo et al. 2002).

In addition, there was another important, but slightly surprising result, a small anomaly detected also in this examined area. As it was already mentioned previously those grassy areas which were directly on the banks of the river, were significantly warmer by a couple ${ }^{\circ} \mathrm{C}$ than the afforested zones, even though the grassy area had an excellent water supply. This proves that such a vegetation structure, which consists of multiple canopy layers, where the solar radiation cannot directly reach the ground surface and thus a colder air layer can evolve between the closed crown canopy layer and the ground surface, has a highly significant cooling effect on the thermal conditions of the given area. This result has been also achieved by researching the inner part of the city in case of a turf and the neighbouring cemetery, which is covered by closed canopy layered treee stand (Olah 2010).

In the case of the small black locust forest (Robinia pseudoacacia) in the $16^{\text {th }}$ District it was first a surprising result to see that this forest has a cooling effect almost as big as the former poplar forest, in spite of the different vaporizing attributes of the two tree species. It is widely known that wattle trees are capable of controlling the rate of their vaporization, while the poplars vaporize as intensely and much as possible. However, this surprisingly great cooling ability can be explained by two causes.

The first cause is the level of the underground water. Although this small black locust forest stands on poor sandy soil, the level of the underground water is relatively high due to the proximity of the Rákos Creek. Thus the necessary water supply is provided for the trees; consequently they do not have to reduce the rate of their vaporization. This high rate of vaporization is the primal component of the significant cooling effect.

The second cause is the age and the size of this tree stand. The height of the young poplar forest was relatively variegated with tree heights between 10-20 metres. Even though the black locust tree stand is relatively old, its final height reaches uniformly only approx. 20 metres. Thus in this case the cooler shaded zone is much thicker, which intensifies the cooling effect.

According to these results it can be stated that the physical structure of the vegetation (height, crown canopy layer, rate of shading, number of the canopy layers) is as important as its rate of vaporization itself. The shading factor is also very momentous in case of very arid (desert or semi-desert) areas, just like the inner part of Mexico, Mexico City. Considering these places during the dry weather, when the rate of evapotranspiration and any other vapourisation is extremely low, the shading effect is that which can momentously reduce the temperature and the heat impact of the incoming radiation. (Oke et al. 1999).

The shading is also very important from the point of view of energetics and energy balance. Manystudies have already concentrated on reduction of the building energy consumption by using solar shading devices and, which is extremely important for especially by using natural solar shading devices i.e. trees (Akbari 2002). 
The case of the black locust (Robinia pseudoacacia) forest zone beside Határ Road was not a surprise at all. The level of the underground water was the lowest here out of all four examined sites. The tree stand is relatively old and well developed, but due to the poor water supply the rate of vaporization is relatively low, much lower than in the previous case. This low rate of vaporization reduces the intensity of the cooling effect which can be detected in the temperature values and heat distribution as well. This means that in some cases the tree stand with the continuous canopy layer is only approx. $3{ }^{\circ} \mathrm{C}$ cooler than the neighbouring garden city which is partially covered by huge old trees. This value is still remarkable and is absolutely coincident with the other measurements of the microclimatic effects of black locust tree stands (Feldhake 2001), which also proves the momentous effect of shading.

There is another reason for the low rate of the cooling effect, which is a consequence of the shape of the forest plot. It is a relatively narrow zone, which separates a brown field from a garden city. The brown field has a significant heating impact on the forest zone, especially in sunny periods. Nevertheless, this relatively small, $3{ }^{\circ} \mathrm{C}$ cooling effect can still be significant in certain cases, especially because it is combined with shading effects as well. This rate only seams small in comparison with the results of the other surveyed sites.

Finally, the Farkas Forest must be mentioned as well. In this case all such positive factors can be found at the same time, which successfully maximize the cooling effect. First of all, even though the soil is sandy and of poor quality, the level of the subsoil water is at an accessible level for the roots. Secondly, the main species of the vegetation are the English oak (Quercus robur) which is a very eurytopic tree (it tolerates both poor soil conditions and aridity very well), but if the water supply is sufficient, its rate of vaporization is extremely high and consequently its cooling effect on its environment becomes significant. The third factor is the age of this tree stand and consequently its well developed height and structure. It is approx. 60 years old; it has a closed crown canopy layer and reaches a height of approx. 30 metres. It also contains multiple canopy layers.

According to the above, all the tree species, the water supply and the physical structure of the tree stand enable the cooling effect to reach its highest possible rate, and consequently this forest is $7-18{ }^{\circ} \mathrm{C}$ cooler than the surrounding areas. This clearly shows that the cooling rate is more than $10^{\circ} \mathrm{C}($ !) on average.

Because of in the case of the Farkas Forest all condition is optimal for the given tree stand type for maximizing its growing speed, evapotranspiration and on this way its cooling effect, this can be a best example in Hungary of the so called Park Cool Island (PCI) which is quite remarkable all over the world almost in all cities (Chang et al. 2007).

A warmer zone, where the crown canopy layer was not continuous, was detected on both two earlier images. However this phenomenon was not detectable on the two latter images. This difference is most probably due to development of the vegetation in the meantime, i.e. the crown canopy layer has changed (it has become almost unbroken) and this is the reason why the thermal cross sections of the latter images do not show these warmer spots anymore.

\section{SUMMARY}

The main species of the vegetation are very important in reaching the greatest potential conditioning effect. Probably, if instead of the wattle tree stand there would be an oak-yard of the same age in the $16^{\text {th }}$ District, the rate of the cooling effect would be stronger. 
It is very interesting to see that the original native tree species (willows, poplars, oaks, ashes, elms) in the valley of the River Danube are exactly those tree species which are capable of vaporizing to the highest rate and at the same time they are eurytopic enough to tolerate the urban circumstances.

The water supply is as important as the tree species themselves. As it has become clear in the case of the black locust forest zone beside Határ Road, if the level of the subsoil water is low and there is no irrigation, the vegetation is physically incapable of such intensive vaporizing and such development, which would be necessary for reaching the potential maximum rate of the conditioning effect.

-The third attribute, which is almost even more important than the two former ones, is the structure of the vegetation and the existance of a continous crown canopy layer. Such a layer sustains a relatively cold and thich air layer above the ground surface, and on the other hand it prevents the solar radiation from directly reaching the ground surface. As it can be seen in the case of the Farkas Forest and the small forest in the $16^{\text {th }}$ District the good structure of the tree stand plays a significant additional role in the cooling effect, which can even eliminate the disadvantage of selecting unsuitable tree species.

Finally, it must be stated that in the planning of urban vegetation the climatic and ecological aspect will become more important than the aesthetic aspect in the future. According to the climatic needs, planning tree stands which incorporate several continuous crown canopy layers and consist of eurytopic and intensely vaporizing species will become fundamental, furthermore the effective methods of providing the necessary water requirements either naturally (by maintaining the high level of the subsoil water) or artificially (by irrigating) will also have to be taken into consideration.

\section{REFERENCES}

Akbari, H. (2002). Shade trees reduce building energy use and $\mathrm{CO}_{2}$ emissions from power plants. Environmental Pollution Vol. 116, Supplement 1, 119-126 p.

Chang, C. R., Li, M. H. \& Chang, S. D. (2007). A preliminary study on the local coolisland intensity of Taipei city parks. Landscape and Urban Planning.Vol. 80, Issue 4, 20, 386-395 p.

Csepely-Knorr, L. (2009). Public Parks in Budapest at the turn of the 19th Century. Paper presented at Lippay- Ormos- Vas Conference full paper book. In Press

Csepely-Knorr, L., Gergely, A. \& Olah, A. B. (2010). The Use of Archive City Plans in Contemporary Urban Planning. Paper presented at ISUF, $17^{\text {th }}$ Conf. Int. Seminar on Urban Form. Hamburg, Germany, 20-24. August 2010.

Dobi, I., Mika, J., Olah, A. B., Lelovics, E., Dezso, Zs., Pongracz, R. \& Bartholy, J. (2009). Cold and hot events in urban environment. Poster presented at ICUC-7, Int. Conf. on Urban Climate. Yokohama, Japan, $29^{\text {th }}$ June $-3^{\text {rd }}$ July 2009. Retrieved 2009-10-3, from http://www.ide.titech.ac.jp/ icuc7/extended_abstracts/index-web.html

Feldhake, C. M. (2001). Microclimate of a natural pasture under planted Robinia pseudoacacia in central Appalachia, West Virginia. Agroforestry systems. Vol. 53, No. 3, 297-303 p.

NASA (1999). Science writers' guide to Terra. NASA Earth Observing System Project Science Office, Greenbelt, MD, Retrieved 2010-05-5, 1999, from: https://lpdaac.usgs. gov/lpdaac/products/aster_products_table/on_demand/surface_radiance _tir/v1/ast_09t 
Ogunjemiyo, S., Roberts, D. A., Keightley, K., Ustin, S. L., Hinckley, T. \& Lamb, B., (2002). Evaluating the relationship between AVIRIS water vapor and poplar plantation evapotranspiration. Journal of Geophysical research, Vol. 107, 4719, 15 pp.

Oke, T. R., Spronken-Smith, R. A., Jáugerui, E. \& Grimmond, C. S. B. (1999). The energy balance of central Mexico City during the dry season. Athmospheric Environment. Vol. 33, Issues 24-25, 3919-3930 p.

Olah, A. B. (2010). Detected Effect of a Newly Constructed Huge Building on the Heat Balance of Its Surroundings. Paper presented at IX. Int. Conf. on Applications of the Natural, Technical and Economical Science, Szombathely, Hungary, $15^{\text {th }}$ May 2010.

Schmidt, G. (2003). Plants in garden design. Mezőgazda, Budapest, pp 162-164.

Szegedi, S., Gyarmati, R. (2009). Impacts of urban green spaces on the spatial structure of the urban heat island in Debrecen and different sized settlements in its neighbourhood. Acta climatologica et chronologica Universitas Szegediensis, Tomus 42-43, 151-158.

Unger, J., Pongracz, R. (2008). Urban Climate Research in Hungary. International Association for Urban Climate, No. 28, 17-20 p. 